\title{
Comparative Political Thought: What Are We Looking At?
}

\author{
Michael Freeden \\ Department of Politics and International Relations, University of Oxford, \\ Oxford, United Kingdom \\ michael.freeden@mansfield.ox.ac.uk
}

\begin{abstract}
Comparative political thought should focus on exploring and interpreting a flexible, pliant and mutating redistribution and re-assembly of political discourses of ideational and cultural significance across the planet. While exploring their local variants, its role is not simply that of decentring or 'provincializing' an era or an historical epoch, but of identifying the major political thought-practices in which all societies engage.
\end{abstract}

\section{Keywords}

comparative political thought - the political - ideologies - interpretation cross-cultural

In its relatively short life to date as an acknowledged disciplinary variant, the study of comparative political thought has taken two fundamental paths. Most scholars dedicated to this enterprise follow the first of these, aiming to expand the limited conventional remit of both political philosophy and the history of political thought in order to include, in an act of cultural emancipation, what is vaguely called non-Western approaches and themes. The second path, however, is not cultural and geographical. It seeks to identify both overarching and distinctive forms and patterns of political thinking wherever they occur. Its purpose is to interrogate and deepen our understanding of that very complex practice, engaged in by all societies at varying levels of intensity and articulation. That approach is no substitute for the first, but it is not primarily concerned with a spatial juxtaposition of differences. Instead, it endeavors to theorize 
about the features and possibilities of a ubiquitous type of thinking that, while adopting different shapes, goes to the heart of the ways we live as social beings.

Accordingly, it holds that political theory stands to benefit considerably from thoroughly investigating the varieties of political thinking. Crucial as geographical location and cultural specificity are, from this second disciplinary perspective - that of social scientists and social philosophers-they are but markers on the road to acquiring and finessing a body of knowledge about the raw material and potential of our discipline. Mecca, Moscow, Mogadishu, Manila, Mexico City, or Montreal all offer comparative insights on matters relating to, say, lending or withholding support for political collectivities. Monarchs, mayors, chieftains, generals, parliamentarians, and trade union heads offer comparative instances of leadership practices that shed light on the intricacy of decision-making procedures embraced by discrete communities. The scopes of acceptable public language in diverse institutional and informal settings point to contrasting as well as common exercises of verbal and written power and the differential speeds in which they can be modified —all grist to the mill of scholarly curiosity. What's more, as comparativists we are still on a voyage of discovery not only to faraway lands but to the streets around us, with their abundant assortment of vernacular and everyday political thought and discourse, as we tackle the separate vocabularies of politicians, academics, bureaucrats, ideologues, lawyers and, more generally, citizens and residents.

It all depends on what we wish to focus: an elaboration of the political, so as to comprehend its myriad forms that nevertheless display common as well as distinct characteristics; or the plural diversity and particular identities of cultures whose significance has been particularly underrated to date in political and philosophical studies. Of course, there clearly exist joint global and cross-cutting national concerns, but on another dimension there also exist shared professional foci whose function it is to extract information of overriding interest to interpretative, rather than advocacy, political theorists. Major differences in research cultures are discernible here. The mission of engagé advocacy theorists, frequently fuelled by outrage over the silencing of entire populations, is to prescribe solutions designed to redress historical wrongs that have held societies and social strata-and their students—in subaltern ideational and material fiefdom. Correcting that is vitally important, but it is nourished on an ethical drive based on what people do, should do, and should not do. By contrast, the mission of interpretative political theorists is that of Verstehen, of learning by means of comparison about how people think politically-irrespective of whether those thoughts may be regarded as decent, principled, distasteful, or bizarre-because the discipline urgently needs to acquaint itself more closely with the unique properties of what political 
thinking entails on our planet. Knowing more about the diverse ways in which those properties manifest themselves is not just a matter of recalibrating the balance among cultures by giving voice to underrepresented ones. It is the alternative challenge of accumulating an array of case studies that illuminate the diversity of the political, through which one can test, appreciate, and refine its core contours. We can and should pursue both paths enumerated above, because political knowledge-production depends on them in conjunction. But we must recognize that the dual foci of comparative political theory supply dissimilar answers to equally valid research and disciplinary questions, even as both those foci shift away from the methodological universalism that has been so central to political philosophy, noble as its normative intentions may have been.

I therefore concur with the editorial statement of this volume that as comparativists we ipso facto enhance the quality of political theory and we do so precisely by replacing the unity and certainty of resolute visions and stipulative standards with the alluring fragility, fragmentation, ruptures, inconsistencies, and idiosyncrasies - alongside the telling commonalities and logics - that inhabit the minds of social beings. The advantage we subsequently gain as political theorists is due not just to integrating cross-cultural perspectives, but also due to an enriched awareness of the intricate practices and patterns of thinking politically (see my The Political Theory of Political Thinking: The Anatomy of a Practice [Oxford: OU P, 2013]). It is not just a (re)discovery of the variety of thinking around us but directly the consequence of recent disciplinary and extra-disciplinary upheavals that have reshaped the study of political thinking and of the ideological configurations through which it is forged and transmitted.

Strictly speaking, then, what we are studying is comparative political thought, or thinking, and incorporating our findings into the body of political theory - namely, the theory that investigates the macro- and micro-components and arrangements of political thinking, practices, and processes in all their forms. There has been some terminological slippage here. That is not the only diffculty. Another is the marked tendency to refer to comparative political theory as a code for non-Western theory and thinking. So, what it says on the tin is not what we find in the tin. Instead of lamentable past exclusions of a group of societies from the comparative urge to study political thought as and where it exists, we now encounter unfortunate and misplaced exclusions of "Western political thought," however loose and unreliable that term may be. The bifurcation that undermined the proper understanding of political thinking remains, and we are all too often still deprived of a fuller range of proper comparative studies. Even then, non-Western countries are frequently and disjointedly assembled 
side-by-side with little attempt to draw broader interconnecting conclusions. Their "default" position in just being "non-Western" is a wholly unconvincing reason for lumping together, say, India, Saudi Arabia, Chad, or China under that heading. The fact that this practice has become so ingrained does no favors to the discipline of political theory; division, truncation, and segmentation impoverish our capacity to learn from all instances of political thought in a comparative register and to separate the disparate from the common.

Rather than simply decentering or "provincializing" an era or an historical epoch, an agenda of comparative political theory should concentrate on a flexible, pliant, and mutating redistribution and re-assembly of discourses of ideational and cultural significance, thus exercising variable choices over what a scholar deems is interesting, unusual, decisive, disruptive-or for that matter repulsive or attractive, if value-judgments must be introduced-about the multiple nodes of such significance, be they clustered around gender, markets, religion, authority sources, conquest, welfare, conceptualizations of the political, and so on. It should explore the unintentional as interwoven with and accompanying deliberate so-called "rational" speech-acts. It should assess the varying criteria of what counts as rational discourse, and its acceptable and unacceptable intermingling with emotional and fantasmic forms of expression. Indeed, what evokes pride, anger, disgust or amusement in collective affairs may differ considerably from place to place, group to group, period to period. These may well be far more evocative, indicative, and colorful than the written word alone. Recognition of such hues as significant vehicles in themselves of political language is a bedrock of comparison. The underlying issue for the researcher is to determine what work these spatially and temporally heterogeneous modes of articulation and communication discharge, and what they fail to discharge, in our understanding of the political.

It is worth noting that the resurgence of the study of ideologies-those ubiquitous forms of thinking about politics, especially in their morphological aspects - has implanted a comparative inevitability into their analysis. In theory, even within the same broad family, ideologies display an infinite variety of conceptual combinations, alerting us to the pliability and indeterminate nature of political thinking - even if they actually appear in broad discernible patterns. Comparison is built into the very awareness of that inherent plasticity, of the absence of fixity in political language and symbolic representations.

Finally, comparison also raises the question of travelling political ideas and conceptions or, put differently, of how the inevitable parochialisms we create collectively fare on arrival elsewhere. It is effectively impossible to arrive at a robust assessment of the battering a particular conception of a concept has received upon touching down, for the question is: what happens when one 
external parochial idea meets an internal one? Who has the larger share of an encounter when the introduction of an external, colonizing set of bureaucratic practices tries to override a local tradition of organized public rules? Who are the radicals here, if any: those who attempt to change extant patterns of thinking, or those who try to tame change? There are strong ideological reasons that postcolonial studies are still in hock to dichotomies such as "hegemonic" and "subaltern" that serve to mask a far greater complexity in the field. And we are confronted with the homogenizing assumption that a recipient culture has its typical local conceptions, rather than recognizing that it too has a melee of competing conceptualizations, all the more so when standardizing technologies are unavailable to it.

As students of the political we may examine the movements of elitist discourses, say Mill's or Marx's writings, among book- and tract-reading minority groups, though we then have to observe how they were chiselled to accommodate local understandings or, conversely, failed to take root. But we may equally note the dissemination of popular slogans and distillations with fast food appeal such as the "Arab spring," "black is beautiful," "the harmonious society," "power to the people." Indeed, what is really parochial may not be exportable; what can move successfully may already be invested with some of the features of the political at the "other end." More often ideas move undercover, embodied in material practices whose rationale, justification, or very existence are not usually thought through: demonstrations, boycotts, queuing, shaking hands versus bowing, clothing customs and uniforms, leisure pursuits, forms of artistic expression. They may be a central preoccupation of cultural anthropologists, but they all have significant political meanings. They legitimate (or delegitimize) modes of political participation, strong and emotionally-laden opposition to certain groups and activities, the regulation of conduct in public spaces, adherence or deference to self- and group-identification through rituals and apparel, acceptable forms of carving out personal spaces for diverse pastimes, or the social limits or public utility criteria imposed on the creative imaginations of individuals. It is in practices such as these-alongside support for political parties, leaders, or even national pride and feelings of exclusivity - that the political is expressed and applied. The overwhelmingly salient perceptions of power, of hierarchy, of control, which appear to dominate the sphere of the political, must not drown out those far subtler and pervasive manifestations of political ideas and practices crying out for key comparative analysis. They too deserve a seat at the inner sanctum of political theory. 